\title{
Antioxidant and Antifibrotic Effect of a Herbal Formulation In Vitro and in the Experimental Andropause via Nrf2/HO-1 Signaling Pathway
}

\author{
Woong Jin Bae, ${ }^{1,2}$ Guan Qun Zhu, ${ }^{2}$ Sae Woong Choi, ${ }^{2}$ Hyun Cheol Jeong, ${ }^{2}$ \\ Fahad Bashraheel, ${ }^{2}$ Kang Sup Kim, ${ }^{2}$ Su Jin Kim, ${ }^{2}$ Hyuk Jin Cho, ${ }^{2}$ U Syn Ha, ${ }^{2}$ \\ Sung Hoo Hong, ${ }^{2}$ Ji Youl Lee, ${ }^{2}$ Hyun-A Oh, ${ }^{3}$ Hye Cheong Koo, ${ }^{3}$ Do Ram Kim, ${ }^{3}$ \\ Sung Yeoun Hwang, ${ }^{3}$ and Sae Woong Kim $^{1,2}$ \\ ${ }^{1}$ Catholic Integrative Medicine Research Institute, College of Medicine, The Catholic University of Korea, Seoul, Republic of Korea \\ ${ }^{2}$ Department of Urology, College of Medicine, The Catholic University of Korea, Seoul, Republic of Korea \\ ${ }^{3}$ KEMIMEDI, Seoul, Republic of Korea
}

Correspondence should be addressed to Sae Woong Kim; ksw1227@catholic.ac.kr

Received 28 April 2017; Revised 3 July 2017; Accepted 25 July 2017; Published 17 September 2017

Academic Editor: Márcio Carocho

Copyright ( 2017 Woong Jin Bae et al. This is an open access article distributed under the Creative Commons Attribution License, which permits unrestricted use, distribution, and reproduction in any medium, provided the original work is properly cited.

\begin{abstract}
The Korean herbal formulation Ojayeonjonghwan is used for improving late-onset hypogonadism (LOH) symptoms such as erectile dysfunction (ED). A previous research suggested that a modified Ojayeonjonghwan (KH-204) could be used as an alternative to the treatment for ED. The pharmacological effects were examined in different conditions, including in vitro and in vivo. We measured the survival rate of TM3 Leydig cells under the oxidative stress condition. The s.c. injection of leuprorelin was used to induce androgen deprivation. We measured serum testosterone levels, oxidative stress, and apoptosis. The results of the treatment by KH-204 (1) preserved TM3 cells from oxidative stress by improving the expression of nuclear factor erythroid 2-related factor 2 (Nrf2)/heme oxygenase-1 (HO-1); (2) lowered the expression of transforming growth factor-beta (TGF- $\beta$ ) 1/ SMAD; (3) increased the average of serum testosterone in androgen-deprived male rats; (4) kept the activation of spermatogenesis; (5) upgraded the contents of 8-hydroxy-20-deoxyguanosine (8-OHdG) and degraded the contents of superoxide dismutase (SOD); and (6) reduced apoptosis. We studied that $\mathrm{KH}-204$ improved testicular dysfunction in LOH. It is likely, at least in part, to degrade oxidative stress through the Nrf2/HO-1 pathway. These findings may offer credible evidences for the use of new alternative therapies to treat $\mathrm{LOH}$.
\end{abstract}

\section{Introduction}

Late-onset hypogonadism $(\mathrm{LOH})$ includes symptoms such as depression, fatigue, low muscle mass, and erectile dysfunction (ED) and occurs in middle-aged males. Many studies have demonstrated that $\mathrm{LOH}$ is closely linked to a deficiency in serum testosterone levels [1-3] because the total number of Leydig cells, which are the main source of testosterone in middle-aged men, decreases to about a half of that seen in young men $[4,5]$. LOH symptoms are associated with testosterone deficiency and, therefore, can be improved by androgen replacement therapy (ART). ART can be used by men with $\mathrm{LOH}$ unless there are contraindications such as unstable cardiovascular disease, prostate cancer, or polycythemia; however, the long-term effects of ART are uncertain. In particular, external testosterone supplementation can contemporaneously increase the incidence of side effects including prostate cancer, benign prostatic hyperplasia (BPH), and cardiovascular events $[5,6]$. ART can impair fertility, so men who would like to start a family 
in the short run should make sure that they should not undergo ART [7].

Traditional herbal medicine is recognized as an alternative treatment of $\mathrm{LOH}$ that avoids the adverse effects of ART and, in some cases, can be of benefit to libido $[8,9]$. Now, male infertility and $\mathrm{LOH}$ symptoms including $\mathrm{ED}$ are usually treated by the herbal formulation Ojayeonjonghwan $[10,11]$. Park et al. [10] illuminated that improved Ojayeonjonghwan, known as KH-204, ameliorated ED caused by peripheral neuropathy in aged and diabetic rats. Recently, we also found that $\mathrm{KH}-204$ protected against oxidative stress in rat testis [12]. A major characteristic of aging is the increased oxidative stress. It has been involved in various age-related pathologies [13]. Regarding interacting proteins and regulatory molecules such as heme oxygenase-1 (HO-1), the nuclear factor erythroid 2-related factor 2 ( Nrf2) signaling system has become the most significant cellular defense mechanism against oxidative stress, and many reports suggest that the reduction in the adaptive response of the Nrf2 signaling system has had a great influence in the cumulation of oxidative damage in aging [14-16].

Some previous studies demonstrated that progressive fibrosis was recognized as a characteristic in various organs, playing an important role during aging $[17,18]$. Transforming growth factor-beta (TGF- $\beta$ ) is considered to have a significant effect in the pathogenic mechanism of diabetes-induced ED. Especially, TGF- $\beta 1$ has been regarded as one of the most relevant fibrogenic cytokines, which is also high expression in the corpus cavernosum of diabetic rats [19]. Zhang et al. [20] also considered that upregulation of the TGF- $\beta 1 / \mathrm{SMAD}$ signaling pathway led to structural changes and decline of erectile function in ED. However, the impact of TGF- $\beta 1 /$ SMAD signaling pathway on Leydig cells including testicular function is still unidentified.

The present study was intended to assess whether KH-204 could protect TM3 Leydig cells through antioxidant activity in vitro and restore testosterone production in an androgen-deprived animal model. In addition, we attempted to identify a potential mechanism of the protective effect.

\section{Materials and Methods}

2.1. Preparation of the Herbal Formula (KH-204). The major ingredients of $\mathrm{KH}-204$ include five plants, as previously described: Cornus officinalis (32\%), Lycium chinense (32\%), Rubus coreanus (16\%), Cuscuta chinensis (16\%), and Schisandra chinensis (4\%). It was manufactured by a company that makes oriental herbal medicines, KEMIMEDI Co. Ltd. (Seoul, Republic of Korea). The quality of KH-204 was confirmed by its marker compound. In addition, the quality of each extract were identified by using high-performance liquid chromatography (HPLC) as previously described [21]. The marker compounds of Cornus officinalis, Lycium chinense, Rubus coreanus, Cuscuta chinensi, and Schisandra chinensis are loganin, betain, ellagic acid, hyperoside, and Schizandrin in HPLC chromatogram, respectively. The manufacturing method and the toxicity data of $\mathrm{KH}-204$ were described in a previous report [22].
2.2. In Vitro Cell Viability and Western Blot Testing Using TM3 Mouse Leydig Cells. TM3 mouse Leydig cells (Korean Cell Line Bank, Seoul, Republic of Korea) were cultured in Dulbecco's modified eagle's medium (DMEM)/F-12 medium $\left(\mathrm{GIBCO}^{\circledR}\right.$, Life Technologies Co., USA) supplemented with $10 \%$ heat-inactivated fetal bovine serum (FBS; GIBCO) at $37^{\circ} \mathrm{C}$. Cells were plated on 96 -well plates (Corning) in $10 \%$ FBS/DMEM/F-12 and incubated for twenty-four hours. They were pretreated with $50 \mu \mathrm{g} / \mathrm{ml}$ of $\mathrm{KH}-204$ for two hours before treating with hydrogen peroxide $\left(40 \mu \mathrm{M} \mathrm{H}_{2} \mathrm{O}_{2}\right)$ for two hours to create oxidative cellular stress. Afterwards, Alamar Blue (Invitrogen, USA) was aseptically added to the cells. The cells were incubated for three hours, and the absorbance of the cells was measured at a wavelength of $570 \mathrm{~nm}$ using an enzyme-linked immunosorbent assay (ELISA) reader (Molecular Devices, USA). The background absorbance was measured at $600 \mathrm{~nm}$ and was then subtracted. Cell viability treated by ERK inhibitor PD98059 or Akt inhibitor LY294002 was also assessed to identify the activation of ERK and Akt.

After processing, we gathered all cellular proteins, by placing cells in a lysis buffer consisting of $0.1 \%$ sodium dodecyl sulfate in phosphate-buffered saline, followed by brief sonication. Protein concentration was identified by a bicinchoninic acid protein assay (Pierce Chemical Co., USA). Thirty micrograms of total cellular protein was separated by $12 \%$ SDS-polyacrylamide gel electrophoresis and then transferred to nitrocellulose membranes. Blots were probed with an antibody specific for the following proteins: $\beta$-actin (1:5000 dilution; Assay Designs, USA); phosphoERK (p-ERK) and total ERK ( $1: 1000$ dilution; Cell Signaling Technology, USA); phospho-Akt (p-Akt) and total Akt (1:500 dilution; Santa Cruz Biotechnology, USA); HO-1 (1:1000 dilution; Cell Signaling Technology, USA); Nrf2 (1:500 dilution; Santa Cruz Biotechnology, USA); SMAD (1:500 dilution; Santa Cruz Biotechnology, USA); and TGF- $\beta$ ( $1: 1000$ dilution; Abcam, UK). The binding antibody of each blot was evaluated by enhancing chemiluminescence (Western blot detection kit; Amersham Pharmacia Biotech, USA), which was assessed with horseradish peroxidaseconjugated secondary antibody.

2.3. Animal Groups and Treatment Protocol. We carried out this experiment strictly following the recommendations in the Guide for the Care and Use of Laboratory Animals of the National Institutes of Health. The protocol was approved by the Institutional Animal Care and Use Committee in the School of Medicine, The Catholic University of Korea.

Sprague-Dawley (SD) male rats aged 8 weeks were randomly divided into 4 groups ( 8 rats in each group), which were submitted to (1) sham operation only (normal control), (2) androgen deprived only (Androgen-dep. control), (3) androgen deprived treated by KH-204 $200 \mathrm{mg} / \mathrm{kg}$ (Androgen-dep. 200), and (4) androgen deprived treated by KH-204 $400 \mathrm{mg} / \mathrm{kg}$ (Androgen-dep. 400). We administered either distilled water (sham operated) or leuprorelin $0.5 \mathrm{mg} / \mathrm{kg}$ subcutaneously once to the backs of androgen-deprived rats. According to previous experimental results, we selected the dosage of leuprorelin [23]. In each group, once-daily oral administration 
was lasted for 4 weeks (distilled water or $\mathrm{KH}-204$ dissolved in distilled water). After 4 weeks, the animals in all groups were sacrificed under anesthetic and testes, epididymides, and blood samples were obtained.

2.4. Measurement of Serum Testosterone Level. Before the rats were sacrificed, venous blood samples were collected from the inferior vena cava and were assayed by an ELISA testosterone detection kit (BioVendor, Czech Republic) to determine the serum testosterone level.

2.5. Testicular Histologic Evaluation and Immunohistochemistry. The fixed and embedded testicular tissues were stained with haematoxylin-eosin, and these were examined under a light microscope. Ten representative sites were selected randomly in seminiferous tubules, and spermatogenic cell density was measured as previously described [24].

Leydig cells were identified by histochemically staining for Leydig cell-specific marker $3 \beta$-hydroxysteroid dehydrogenase $(3 \beta$-HSD) [25]. On each occasion, tissue sections in each experimental group were immunostained and the intensity of the immunostaining was scored using a simplified scale ranging from negative $(-)$ through weakly positive $(+)$ to intensely positive $(+++)$, as previously described [26].

2.6. Measurement of Oxidative Stress. Oxidative stress was assessed by measuring the 8-hydroxy-2-deoxyguanosine (8-OHdG) content and superoxide dismutase (SOD) activity quantitatively. Total DNA was extracted from the testis using the DNeasy Blood \& Tissue kit (Qiagen, Valencia, CA, USA). The level of $8-\mathrm{OHdG}$ was measured with a DNA oxidation kit (Highly Sensitive 8-OHdG Check ELISA; Japan Institute for the Control of Aging, Fukuroi, Japan). After the final color was developed with the addition of $3,3^{\prime}, 5,5^{\prime}$-tetramethylbenzidine, absorbance was measured at $450 \mathrm{~nm}$. Tissue sample concentration was measured from a standard curve and corrected for DNA concentration. SOD activity (CuZnSOD and Mn SOD) in tissues was determined using an SOD Assay Kit-WST (Dojindo), and the decrease in the rate of the superoxide-mediated reduction of nitroblue tetrazolium was monitored at $450 \mathrm{~nm}$ using a spectrophotometer.

2.7. Assessment of Apoptosis. Testicular tissue sections were washed out with PBS after blocking with $0.1 \%$ Triton X-100 last $5 \mathrm{~min}$. Terminal deoxyribonucleotidyl transferase-mediated dUTP-digoxigenin nick-end labeling (TUNEL, ApopTag In Situ Apoptosis Detection Kits; Millipore, MA, USA) detection solution was dropped on each section and then incubated at $37^{\circ} \mathrm{C}$ in the dark which lasted for an hour. Nuclear staining with DAPI was performed last for $5 \mathrm{~min}$ after being washed out with PBS, and the sections were fixed with $50 \%$ glycerol after being washed out with PBS. For the control sections, the TUNEL solution was replaced with PBS. The sections were observed under a fluorescence microscope.

2.8. Western Blot Testing In Vivo. We gathered testicular tissue proteins of each group, by placing crushed testicular tissues in an ice-cold lysis buffer consisting of $0.1 \%$ sodium dodecyl sulfate in phosphate-buffered saline, followed by brief sonication. Protein concentration was identified by a bicinchoninic acid protein assay (Pierce Chemical Co., USA). Thirty micrograms of total testicular tissue protein was separated by $12 \%$ SDS-polyacrylamide gel electrophoresis and then transferred to nitrocellulose membranes. Blots were probed with an antibody specific for the following proteins: $\beta$-actin (1:5000 dilution; Assay Designs, USA); HO-1 ( $1: 1000$ dilution; Cell Signaling Technology, USA); Nrf2 (1:500 dilution; Santa Cruz Biotechnology, USA); SMAD (1:500 dilution; Santa Cruz Biotechnology, USA); and TGF- $\beta$ ( $1: 1000$ dilution; Abcam, UK). The binding antibody of each blot was evaluated by enhancing chemiluminescence (Western blot detection kit; Amersham Pharmacia Biotech, USA), which was assessed with horseradish peroxidaseconjugated secondary antibody.

2.9. Statistical Analysis. Statistical analyses were carried out using SPSS 16.0 (SPSS Inc., Chicago, USA). The data was expressed as mean \pm standard deviation. Statistical significance was analyzed by the ANOVA test, with group comparisons made by Scheffe's test. $p<0.05$ was considered significant.

\section{Results}

3.1. KH-204 Protected TM3 Leydig Cells against Oxidative Stress via Decreased Expression of TGF- $\beta 1 / S M A D$ and Increased Nrf2/HO-1 Expression. As shown in Figure 1(a), cell viability significantly decreased under the $\mathrm{H}_{2} \mathrm{O}_{2}$ incubation, compared to the cells in none $\mathrm{H}_{2} \mathrm{O}_{2}$ condition $(p<0.05)$. Cell viability was raised to $94 \%$ by the addition of KH-204 but was slightly decreased by pretreatment with the ERK inhibitor PD98059 or the Akt inhibitor LY294002.

Western blot analysis was used to assess whether KH-204 could keep TM3 cells from $\mathrm{H}_{2} \mathrm{O}_{2}$-induced damage. The phosphorylation levels of ERK and Akt were significantly upgraded by KH-204 treatment $(p<0.05$, Figure 1(b)). However, treatment with the Akt inhibitor LY294002 decreased the phosphorylation levels by inhibiting PI3K in the treatment group. These results showed that $\mathrm{KH}-204$ could effectively protect against $\mathrm{H}_{2} \mathrm{O}_{2}$-induced damage via ERK and Akt activation. The quantitative result showed that expression of TGF- $\beta 1 /$ SMAD was significantly increased and Nrf2/HO-1 was meaningfully decreased after $\mathrm{H}_{2} \mathrm{O}_{2}$ injury $(p<0.05$, Figure $2(\mathrm{~b}))$. And this result illuminated that the effect of recovery was according to the dose of $\mathrm{KH}-204$, which means the result is better in the $\mathrm{H}_{2} \mathrm{O}_{2}+\mathrm{KH}-20440 \mu \mathrm{g}$ group than in the $\mathrm{H}_{2} \mathrm{O}_{2}+\mathrm{KH}-20410 \mu \mathrm{g}$ group. In the animal experiment, the Western blot results (Figures 2(c) and 2(d)) showed that expression of TGF- $\beta 1 /$ SMAD was significantly increased and Nrf2/HO-1 was meaningfully decreased after treatment by leuprorelin $(p<0.05)$. However, with treatment of $\mathrm{KH}-204$, the results of protein expression significantly changed, which turned to normality $(p<0.05$, Figures 2(c) and 2(d)).

3.2. KH-204 Preserved Testicular Function and Serum Testosterone Levels in an In Vivo Model. There were no significant differences in body weight among the test 


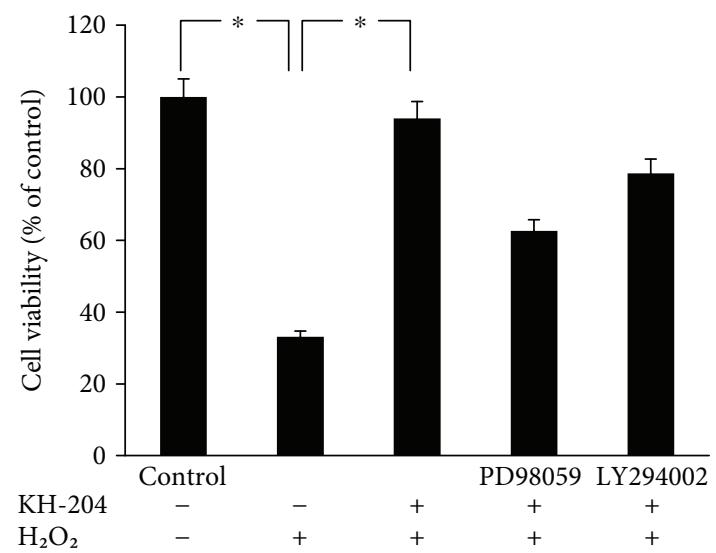

(a)
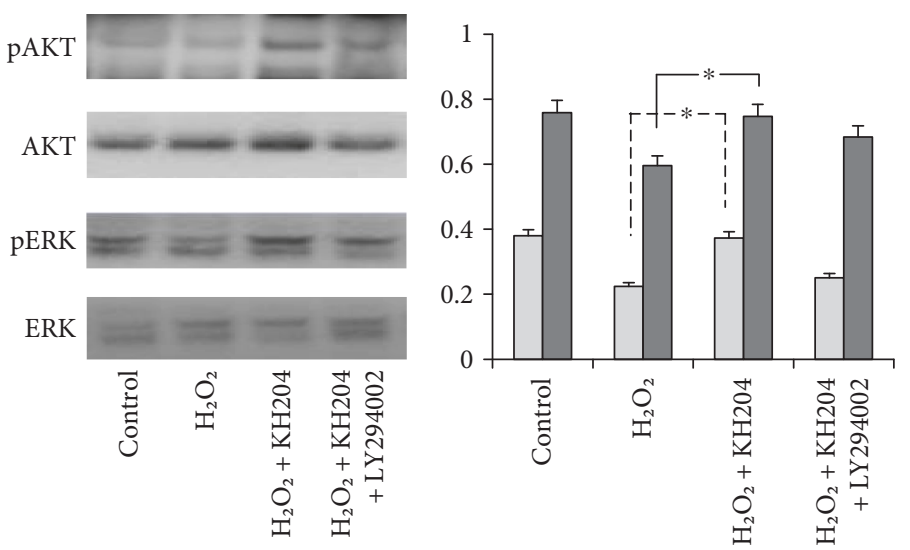

$\square \mathrm{pAKT/AKT}$

$\square \mathrm{pERK} / \mathrm{ERK}$

(b)

Figure 1: (a) Protective effect of KH-204 against oxidative stress. (b) Enhanced activation of ERK and Akt by KH-204 after $24 \mathrm{~h}$ of treatment. The difference was statistically significant $\left({ }^{*} p<0.05\right)$. And the experiments were repeated for three times.

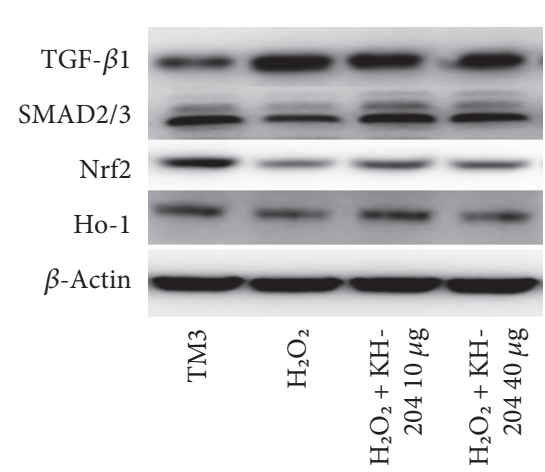

(a)

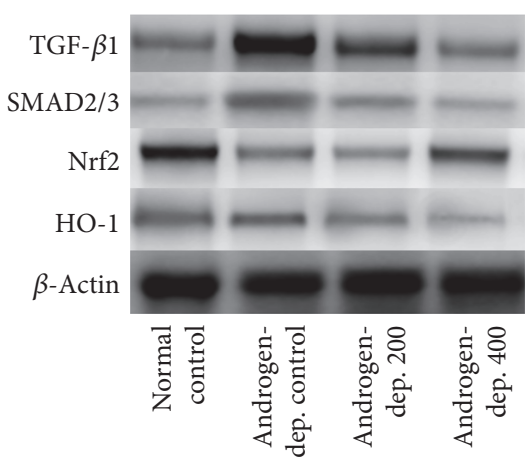

(c)

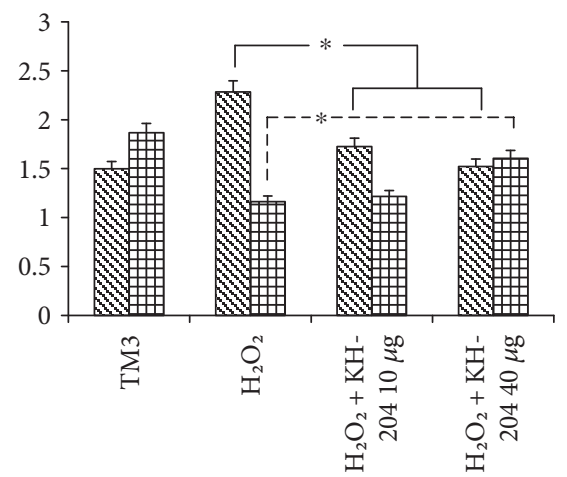

\$ TGF- $\beta 1 /$ SMAD

田 Nrf2/HO-1

(b)

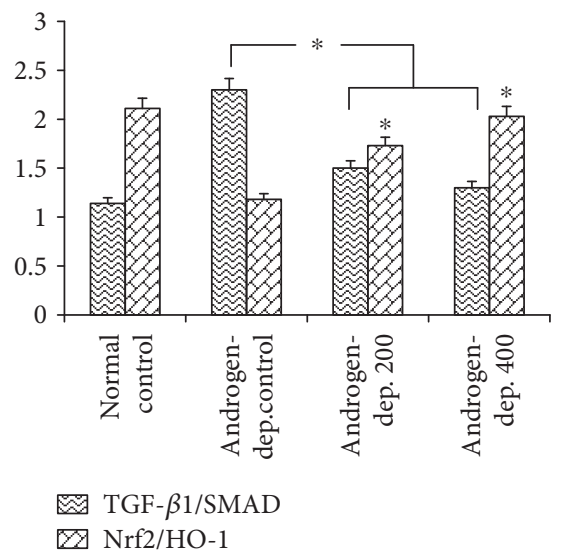

(d)

FIgURE 2: Comparison of the expression levels in vitro and in vivo. (a) is TGF- $\beta 1 / \mathrm{SMAD}$ and Nrf2/HO- 1 in vitro, (b) is densitometric analysis relative to $\beta$-actin in vitro, (c) is TGF- $\beta 1 / \mathrm{SMAD}$ and Nrf2/HO-1 in vivo, and (d) is densitometric analysis relative to in vivo. The difference was statistically significant $\left({ }^{*} p<0.05\right)$. And the experiments were repeated for three times. 
TABLE 1: Comparisons of parameters of the testicular health.

\begin{tabular}{lccccc}
\hline & $\begin{array}{c}\text { Testicular } \\
\text { weight }(\mathrm{g})\end{array}$ & $\begin{array}{c}\text { Epididymal } \\
\text { weight }(\mathrm{g})\end{array}$ & $\begin{array}{c}\text { Germinal cell layer } \\
\text { thickness }(\mu \mathrm{m})\end{array}$ & $\begin{array}{c}\text { Diameter of seminiferous } \\
\text { tubules }(\mu \mathrm{m})\end{array}$ & $\begin{array}{c}\text { Serum testosterone } \\
(\mathrm{ng} / \mathrm{ml})\end{array}$ \\
\hline Normal control & $1.62 \pm 0.19$ & $0.68 \pm 0.03$ & $73.22 \pm 6.34$ & $297.34 \pm 4.33$ & $2.48 \pm 0.41$ \\
Androgen-dep. control & $1.09 \pm 0.06^{*}$ & $0.40 \pm 0.08^{*}$ & $42.19 \pm 2.69^{*}$ & $251.16 \pm 3.62^{*}$ & $1.28 \pm 0.34^{*}$ \\
Androgen-dep. 200 & $1.15 \pm 0.17$ & $0.45 \pm 0.06$ & $52.46 \pm 3.92$ & $271.31 \pm 1.36$ & $1.32 \pm 0.52$ \\
Androgen-dep. 400 & $1.30 \pm 0.05^{* *}$ & $0.59 \pm 0.01^{* *}$ & $69.86 \pm 7.10^{* *}$ & $280.14 \pm 8.32^{* *}$ & $1.72 \pm 0.13^{* *}$ \\
\hline
\end{tabular}

Data show the mean \pm s.d. analysis of variance test. ${ }^{*}$ Significant statistical difference $(p<0.05)$ compared with the normal control group. ${ }^{* *}$ Significant statistical difference $(p<0.05)$ compared with the androgen-deprived control group.

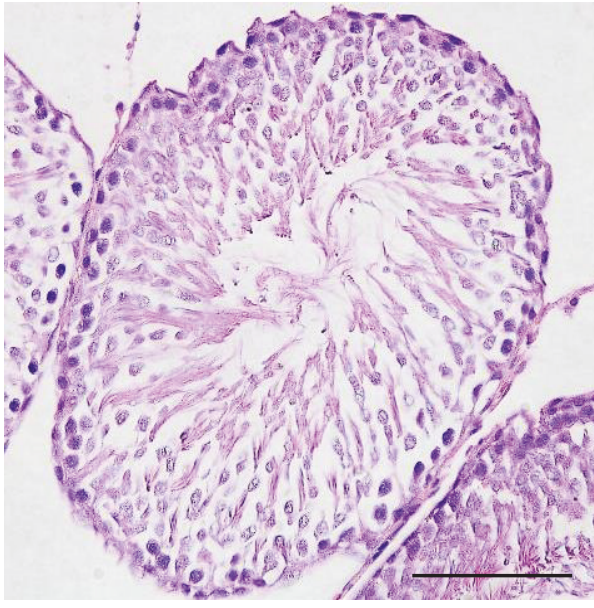

(a)

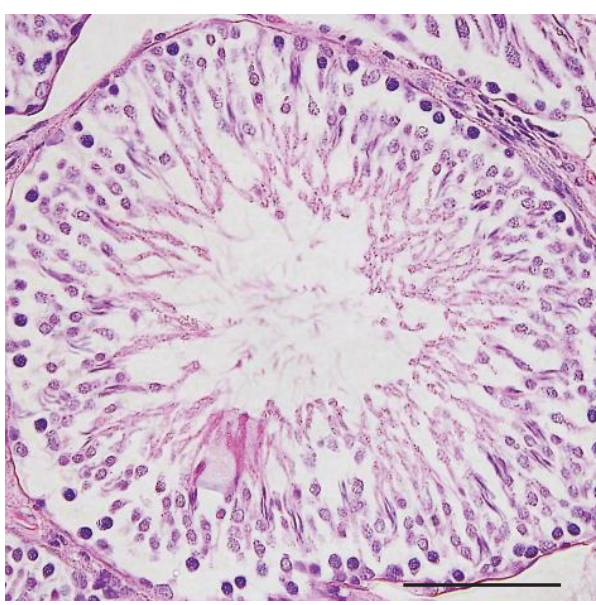

(c)

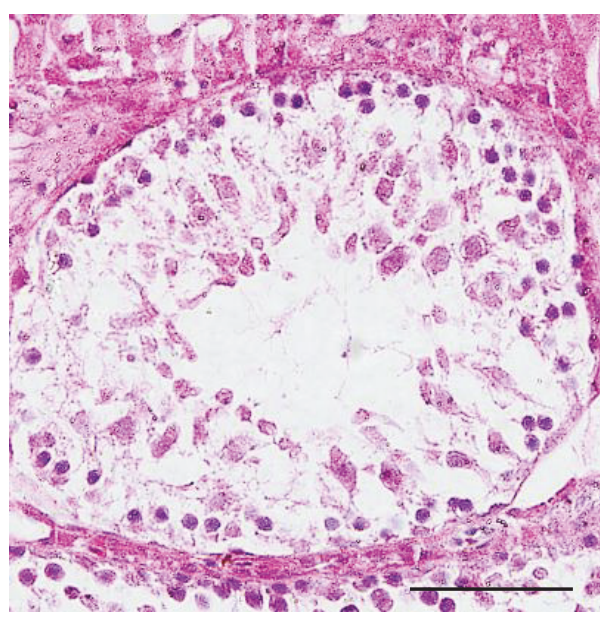

(b)

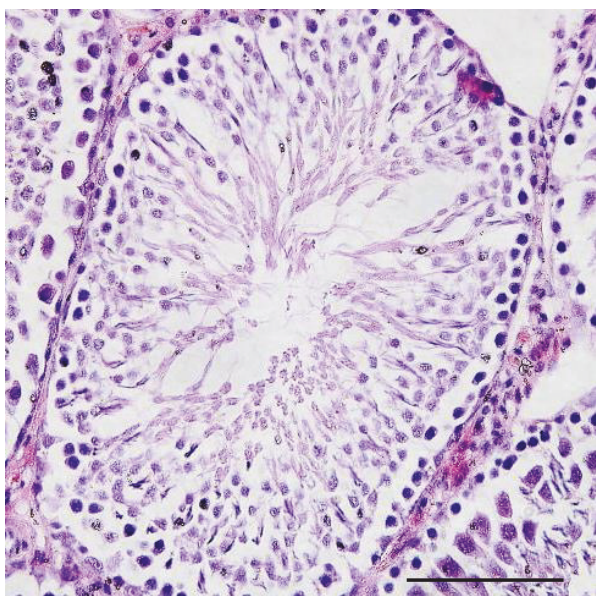

(d)

FIGURE 3: Histopathological findings of the testicular tissues (haematoxylin and eosin stain) in (a) the normal control group ( $n=8$, normal conrtol), (b) the androgen-deprived control group ( $n=8$, Androgen-dep. control), (c) the androgen-deprived $200 \mathrm{mg} / \mathrm{kg}$ group ( $n=8$, Androgen-dep. 200), and (d) the androgen-deprived $400 \mathrm{mg} / \mathrm{kg}$ group $(n=8$, Androgen-dep. 400). Compared with the normal control group, a narrow germinal cell layer is observed in the androgen-deprived control group. Scale bars shown in each figure represent $100 \mu \mathrm{m}$. And the experiments were repeated for three times.

groups. In Table 1, the mean weights of the testis of each group and the epididymis are listed. There was a sensible difference in the testicular and the epididymal weights between the normal control group and the androgendeprived control group after 4 weeks $(p<0.05)$. However, treatment by KH-204 caused obvious increases in testicular and epididymal weights in the androgen-deprived $400 \mathrm{mg} / \mathrm{kg}$ group when compared with those in the androgen-deprived control group $(p<0.05)$.

The testicular tissues of all groups showed normal structure with mature seminiferous tubules and complete spermatogenic series. However, the spermatogenic cell densities of the testes in the androgen-deprived control group were slightly reduced in comparison with those in the other 3 groups (Figure 3 ). 


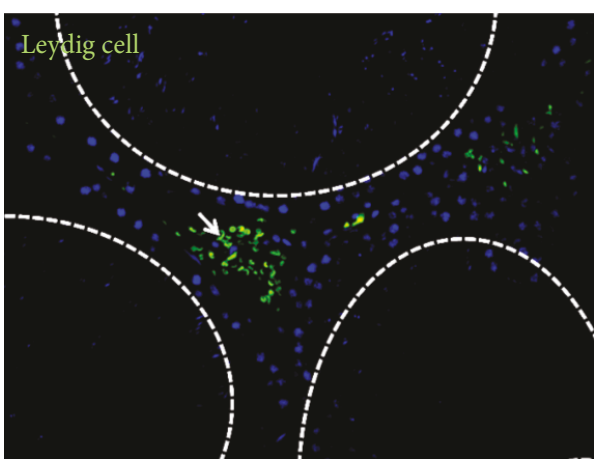

(a)

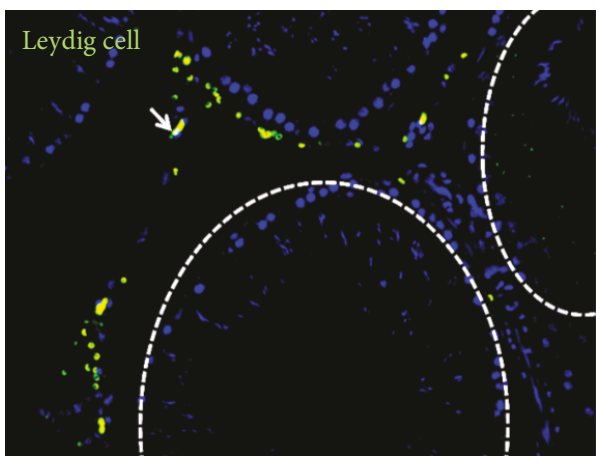

(c)

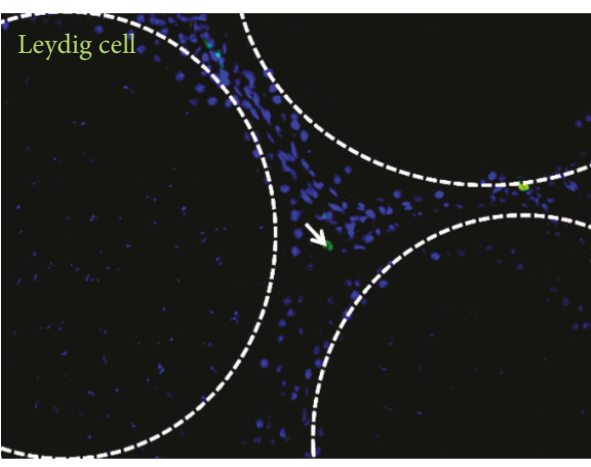

(b)

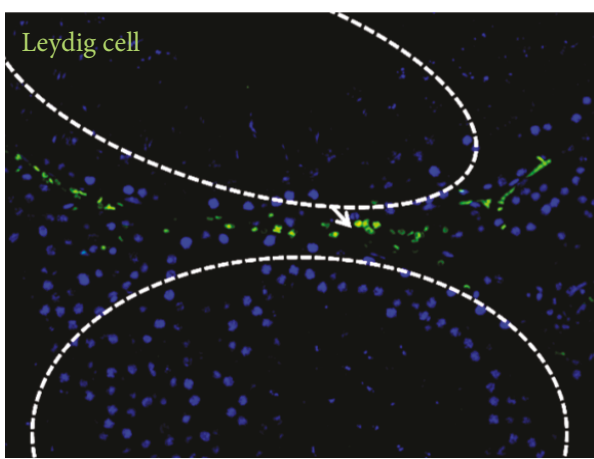

(d)

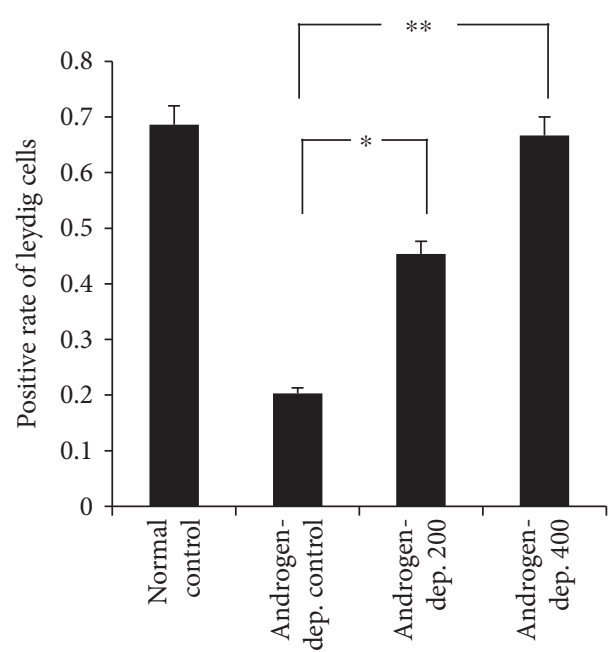

(e)

FIGURE 4: Immunoexpression of $3 \beta$-HSD (arrow) in Leydig cells of rat testis after treatment. $\times 400$. (a) The normal control group ( $n=8$, normal control); (b) the androgen-deprived control group ( $n=8$, Androgen-dep. control); (c) the androgen-deprived $200 \mathrm{mg} / \mathrm{kg}$ group ( $n=8$, Androgen-dep. 200); (d) the androgen-deprived $400 \mathrm{mg} / \mathrm{kg}$ group $(n=8$, Androgen-dep. 400); and (e) positive rate of 3 $\beta$-HSDimmunoreactive cells. The difference was statistically significant $\left({ }^{*} p<0.05\right.$ and $\left.{ }^{* *} p<0.01\right)$. And the experiments were repeated for three times.

The tissue was degenerated, and incomplete spermatogenic series were shown in some seminiferous tubules. There were almost normal mature active seminiferous tubules with complete spermatogenic series in the treatment group. The mean thickness of the germinal cell layer and the mean diameter of the seminiferous tubules in the androgen-deprived $400 \mathrm{mg} / \mathrm{kg}$ group were significantly increased in comparison with those in the androgen-deprived control group (Table 1).

The serum testosterone levels in the androgen-deprived control group were obviously decreased in comparison with those in the normal control group $(p<0.05$, Table 1$)$. These values were dose dependently increased after $\mathrm{KH}-204$ treatment, and those from the androgen-deprived $400 \mathrm{mg} / \mathrm{kg}$ group were significantly increased compared with those from androgen-deprived control group $(p<0.05)$.

3.3. Immunohistochemistry. Cells positive for $3 \beta$-HSD activity are shown in Figures 4(a), 4(b), 4(c), and 4(d). They can be seen in the testicular interstitium, and the intensity was significantly decreased after androgen deprivation. 


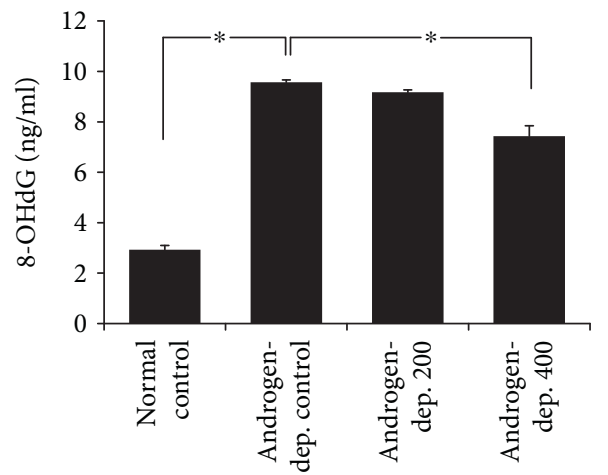

(a)

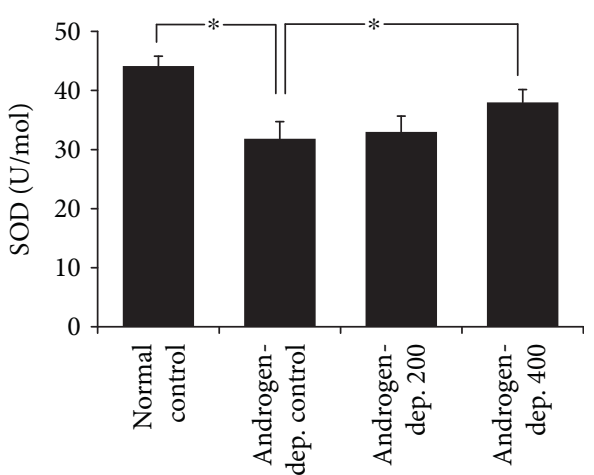

(b)

Figure 5: Comparison of the expression levels of $8-\mathrm{OHdG}(\mathrm{a})$ and SOD (b). The difference was statistically significant $\left({ }^{*} p<0.05\right)(n=8$, in each group). And the experiments were repeated for three times.

However, the number of $3 \beta$-HSD-immunoreactive cells was relatively increased after KH-204 treatment $(p<0.05$, Figure $4(\mathrm{e}))$. Moreover, the intensity in the androgendeprived $400 \mathrm{mg} / \mathrm{kg}$ group was comparable to that in the normal control group.

3.4. KH-204 Decreased Oxidative Stress and Apoptosis. The mean expression of $8-\mathrm{OHdG}$ and SOD is shown in Figure 5. After treatment by KH-204, a dose-dependent decrease in oxidative stress was found. Oxidative stress significantly increased in the androgen-deprived control group in comparison with that in the normal control group but obviously reduced in the androgen-deprived $400 \mathrm{mg} / \mathrm{kg}$ group after treatment $(p<0.05)$. The apoptotic cells in the testis were observed as being dark red in color in the TUNEL assay (Figure 6). The increased apoptotic cells in the androgen-deprived control group were significantly reduced in the two treatment groups receiving a dose of KH-204 $(p<0.05)$.

\section{Discussion}

The present study showed that KH-204 increased the viability of TM3 cells in oxidative-stressed conditions. LOH that bothers many middle-aged males is mainly caused by serum levels of testosterone that decline with age. In the aging male, serum testosterone continues to decrease because of reduced function of Leydig cells [27]. Although the age-related mechanism which could induce decreased function of Leydig cells remains unclear, our data suggest that there is a possibility to change the redox balance of the Leydig cells [28]. In this study, we showed that $\mathrm{KH}-204$ increased the viability of TM3 cells under oxidative-stressed conditions in vitro and in vivo, which means $\mathrm{KH}-204$ can protect the Leydig cells against damage from oxidative stress response. What is more, we detected the testicular function, serum testosterone levels, oxidative stress, and apoptosis in androgen-deprived rats, and these results illuminated that $\mathrm{KH}-204$ could improve the survival of Leydig cells under androgendeprived conditions in vivo.
Some researchers studied the shifts in Nrf2/electrophile response element activity in older organisms. Suh et al. [29] showed that protein expression of $\mathrm{Nrf} 2$ was reduced obviously, combined with a decreased GCL expression. The similar results were also observed in another study, which nuclear Nrf2 was reduced in the aorta of elder groups, along with reduced glutamate cysteine ligase, NADPH:quinone oxidoreductase-1, and HO-1 levels [30]. Although there is no report on the shifts in the expression levels of HO-1 with older testis, we found that the levels of $\mathrm{Nrf} 2 / \mathrm{HO}-1$ were obviously reduced after oxidative stress and ameliorated with the treatment of KH-204 in TM3 Leydig cells.

To examine if $\mathrm{KH}-204$ can increase androgen synthesis in the androgen-deprived rat, we analyzed influences of $\mathrm{KH}-204$ on the contents of serum testosterone and $3 \beta-\mathrm{HSD}$ activities. The present data show that the testosterone concentration and the number of $3 \beta$-HSD-immunoreactive cells were significantly increased after treatment with $\mathrm{KH}-204$, suggesting a protective effect for $\mathrm{KH}-204$. These findings also support the possibility that an increase in serum testosterone might be induced by the protective actions of KH-204 on Leydig cells which could express testosterone in the testis. KH-204 simultaneously increased spermatogenesis and the germinal cell layer thickness. The active sperm production was influenced by the contents of serum testosterone which could upgrade the efficiency of differentiation and active maturation in germ cell [31]. Therefore, consistent with results from previous studies, we suggest that the improved activity of Leydig cells along with the increased serum testosterone levels by $\mathrm{KH}-204$ might improve spermatogenesis.

Aging is along with reproductive dysfunction where there are significant declines in steroidogenesis, spermatogenesis, and sexual function that might be due to the degradation of testicular function $[32,33]$. Although the aging mechanism is confusing, there are commonly held beliefs that two major factors in aging are oxidative stress and apoptosis [34, 35]. Lesniewski et al. [36] found that oxidative stress in cells gradually increased with age in mice. Apoptosis is defined as a kind of biochemical and morphological change in various cellular levels, leading to the removing of unnecessary cells. 

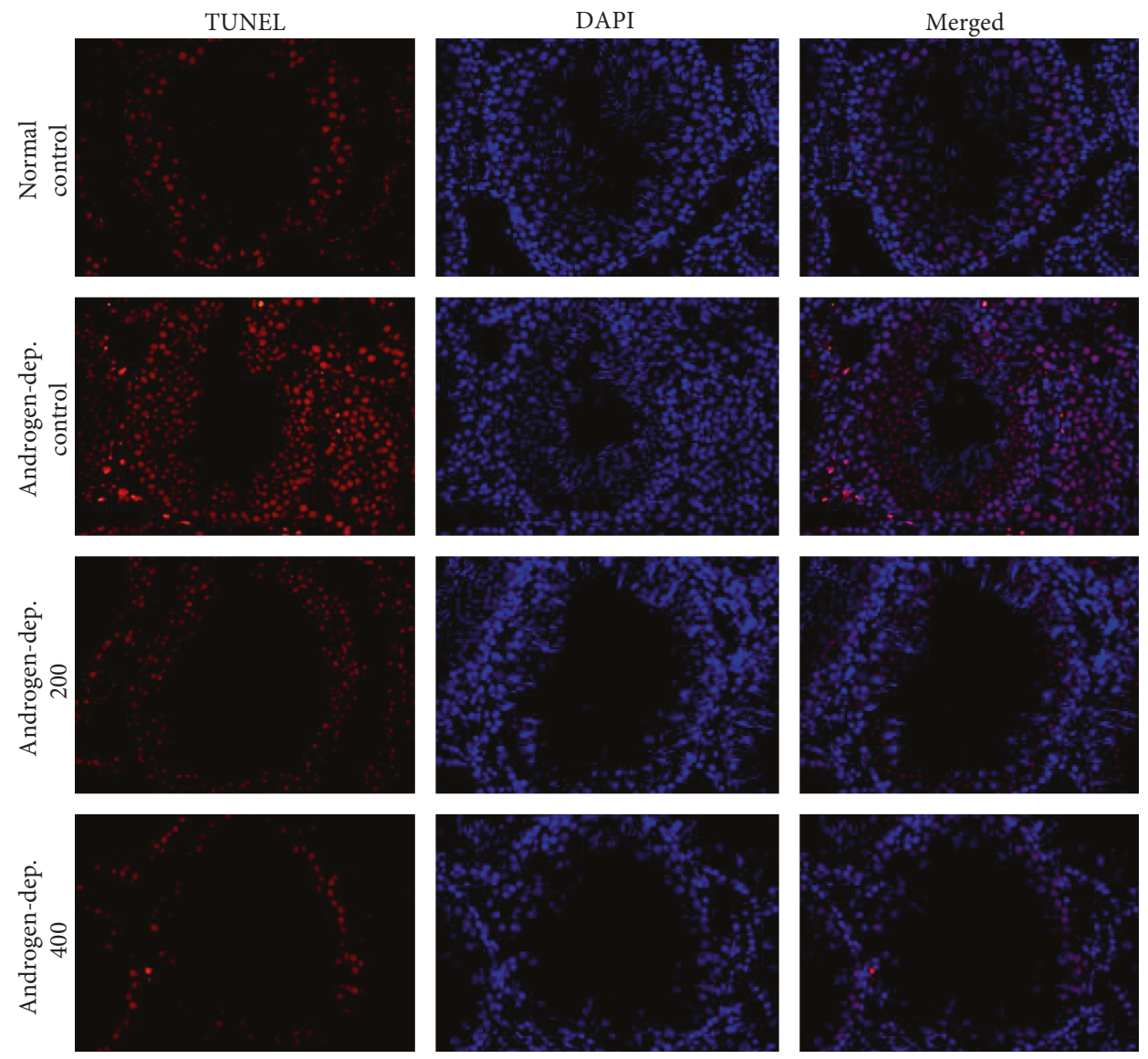

(a)

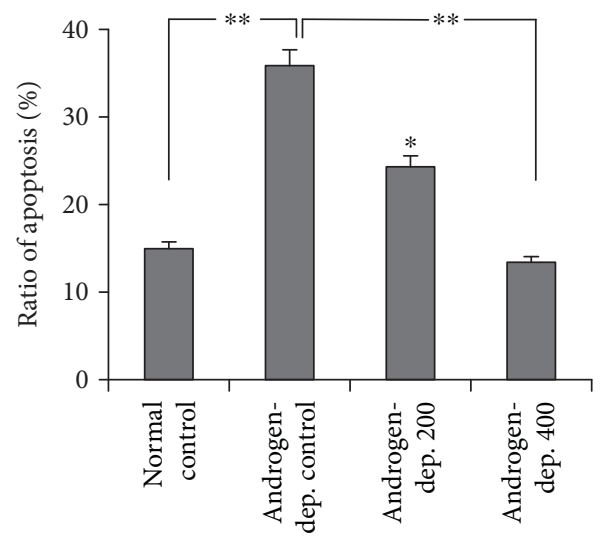

(b)

Figure 6: Effect of KH-204 on testicular tissue apoptosis by TUNEL assay. The difference was statistically significant $\left({ }^{*} p<0.05\right.$ and $\left.{ }^{* *} p<0.01\right)(n=8$, in each group). And the experiments were repeated for three times.

It is an important physiological process [37]. However, apoptosis also has an unwanted influence on aging as it often eliminates important cells that are related to aging [38]. We observed that levels of $8-\mathrm{OHdG}$ degraded and levels of SOD upgraded and that apoptotic cells were significantly decreased following treatment with $\mathrm{KH}-204$ compared with the androgen-deprived group. KH-204 may alleviate testicular dysfunction in androgen-deprived rats via suppression of oxidative stress and apoptosis.
Recent data suggested that there might be a joint pathway for these different tissue damages, which was known as the upregulation of TGF- $\beta 1 /$ SMAD signaling pathway $[20,39]$. As is known to all, TGF- $\beta$ can intermediate its fibrotic effects by triggering the receptor-associated SMADs [40]. Although there is no report on the effect of TGF- $\beta 1 /$ SMAD pathway on the testis, many reports investigated that it might play a key role in configurational changes for erection [41, 42]. In our study, the expression of TGF- $\beta 1 / \mathrm{SMAD}$ was higher after 
$\mathrm{H}_{2} \mathrm{O}_{2}$ injury, and these proteins' contents were obviously reduced in the $\mathrm{KH}-204$ treatment groups in comparison with the group without $\mathrm{KH}-204$. It is likely that $\mathrm{KH}-204$ is at least in part attributable to the antifibrotic effect in the testis.

Herbs have been used widely in various urologic diseases, and many researches have been carried out to prove their safety and efficacy [43]. In particular, herbal medicines such as $\mathrm{KH}-204$ are more essential for the treatment of $\mathrm{LOH}$ due to the adverse effects of ART. Discovery of natural products or herbs that can protect Leydig cells and restore the production of serum testosterone is very important to improve LOH. Previous studies demonstrated that KH-204 ameliorated ED in aged and diabetic rats $[10,11]$. We also found that $\mathrm{KH}-204$ protected against oxidative stress in the cryptorchid testis [12]. However, few studies on the detailed mechanisms against LOH have been reported. The major ingredients in $\mathrm{KH}-204$ were reported to have antioxidant effects in various diseases. Furthermore, it was shown in a previous study that Cuscuta chinensis Lam. might improve kidney yang deficiency symptoms by recovering decreased serum testosterone [44]. In this study, we identified that $\mathrm{KH}-204$ treatment improved the viability in oxidative stressed TM3 cells and that the activation of the ERK/Akt-dependent signaling pathways is the main mechanism. Thereafter, we illuminated that treatment with $\mathrm{KH}-204$ can reduce oxidative stress or apoptosis in the androgen-deprived rat model.

Our study does have some limitations. First, the model used is far from a definite model of LOH. Aged or castrated animals have commonly been used as $\mathrm{LOH}$ animal models in many studies for oral supplementation $[45,46]$. However, we wanted to reproduce a partial androgen deficiency state rather than an entire castration, and low-dose leuprorelin injection was useful for creating this situation. Secondly, while we clarified antioxidant and antifibrotic functions for $\mathrm{KH}-204$, we did not identify the assumed mechanism, through the animal model. In the next work, we should try our best to investigate the accurate mechanism of $\mathrm{KH}-204$ in the $\mathrm{LOH}$ animal model to plan for a clinical study.

We studied the efficacy of $\mathrm{KH}-204$ to improve testicular dysfunction in LOH. The efficacies of KH-204 are likely, at least in part, to degrade oxidative stress through the Nrf2/ HO-1 pathway. These findings may offer credible evidences for the use of new alternative therapies to treat $\mathrm{LOH}$.

\section{Conflicts of Interest}

The authors have no actual or potential conflict of interest associated with this work.

\section{Acknowledgments}

This work was supported by a grant from the NextGeneration BioGreen 21 Program (no. PJ011290012016), Rural Development Administration, Republic of Korea.

\section{References}

[1] C. Wang, E. Nieschlag, R. Swerdloff et al., "Investigation, treatment, and monitoring of late-onset hypogonadism in males: ISA, ISSAM, EAU, EAA, and ASA recommendations," European Urology, vol. 55, no. 1, pp. 121-130, 2009.

[2] H. A. Feldman, C. Longcope, C. A. Derby et al., "Age trends in the level of serum testosterone and other hormones in middleaged men: longitudinal results from the Massachusetts male aging study," The Journal of Clinical Endocrinology and Metabolism, vol. 87, no. 2, pp. 589-598, 2002.

[3] A. Gray, H. A. Feldman, J. B. McKinlay, and C. Longcope, "Age, disease, and changing sex hormone levels in middleaged men: results of the Massachusetts male aging study," The Journal of Clinical Endocrinology and Metabolism, vol. 73, no. 5, pp. 1016-1025, 1991.

[4] W. B. Neaves, L. Johnson, J. C. Porter, C. R. Parker Jr., and C. S. Petty, "Leydig cell numbers, daily sperm production, and serum gonadotropin levels in aging men," Journal of Clinical Endocrinology and Metabolism, vol.59, no. 4,pp.756-763, 1984.

[5] R. Vigen, C. I. O'Donnell, A. E. Barón et al., "Association of testosterone therapy with mortality, myocardial infarction, and stroke in men with low testosterone levels," JAMA, vol. 310, no. 17, pp. 1829-1836, 2013.

[6] A. Barqawi and E. D. Crawford, "Testosterone replacement therapy and the risk of prostate cancer. Is there a link?," International Journal of Impotence Research, vol. 18, no. 4, pp. 323-328, 2006.

[7] J. J. McGill, D. A. Shoskes, and E. S. Sabanegh, "Androgen deficiency in older men: indications, advantages, and pitfalls of testosterone replacement therapy," Cleveland Clinic Journal of Medicine, vol. 79, no. 11, pp. 797-806, 2012.

[8] K. Gauthaman, P. G. Adaikan, and R. N. Prasad, "Aphrodisiac properties of Tribulus terrestris extract (Protodioscin) in normal and castrated rats," Life Sciences, vol. 71, no. 12, pp. 1385-1396, 2002.

[9] T. Amano, T. Imao, and K. Takemae, "Clinical efficacy of Japanese traditional herbal medicine (Kampo) in patients with late-onset hypogonadism," The Aging Male, vol. 13, no. 3, pp. 166-173, 2010.

[10] C. S. Park, S. D. Ryu, and S. Y. Hwang, "Elevation of intracavernous pressure and NO-cGMP activity by a new herbal formula in penile tissues of aged and diabetic rats," Journal of Ethnopharmacology, vol. 94, no. 1, pp. 85-92, 2004.

[11] D. W. Sohn, H. Y. Kim, S. D. Kim et al., "Elevation of intracavernous pressure and NO-cGMP activity by a new herbal formula in penile tissues of spontaneous hypertensive male rats," Journal of Ethnopharmacology, vol. 120, no. 2, pp. 176180, 2008.

[12] W. J. Bae, U. S. Ha, K. S. Kim et al., "Effects of KH-204 on the expression of heat shock protein 70 and germ cell apoptosis in infertility rat models," BMC Complementary and Alternative Medicine, vol. 14, p. 367, 2014.

[13] H. Zhang, K. J. Davies, and H. J. Forman, "Oxidative stress response and Nrf2 signaling in aging," Free Radical Biology and Medicine, vol. 88, Part B, pp. 314-336, 2015.

[14] D. Volonte, Z. Liu, P. M. Musille et al., "Inhibition of nuclear factor-erythroid 2-related factor (Nrf2) by caveolin-1 promotes stress-induced premature senescence," Molecular Biology of the Cell, vol. 24, no. 12, pp. 1852-1862, 2013.

[15] M. El Assar, J. Angulo, and L. Rodriguez-Manas, "Oxidative stress and vascular inflammation in aging," Free Radical Biology and Medicine, vol. 65, pp. 380-401, 2013.

[16] S. S. Gounder, S. Kannan, D. Devadoss et al., "Impaired transcriptional activity of Nrf2 in age-related myocardial oxidative 
stress is reversible by moderate exercise training," PLoS One, vol. 7, no. 9, article e45697, 2012.

[17] N. Gagliano, B. Arosio, D. Santambrogio et al., "Age-dependent expression of fibrosis-related genes and collagen deposition in rat kidney cortex," The Journals of Gerontology. Series A, Biological Sciences and Medical Sciences, vol. 55, no. 8, pp. B365-B372, 2000.

[18] K. A. Cieslik, J. Trial, S. Carlson, G. E. Taffet, and M. L. Entman, "Aberrant differentiation of fibroblast progenitors contributes to fibrosis in the aged murine heart: role of elevated circulating insulin levels," The FASEB Journal, vol. 27, no. 4, pp. 1761-1771, 2013.

[19] G. J. Ahn, Y. S. Sohn, K. K. Kang et al., “The effect of PDE5 inhibition on the erectile function in streptozotocin-induced diabetic rats," International Journal of Impotence Research, vol. 17, no. 2, pp. 134-141, 2005.

[20] X. M. Zhang, P. H. Shi, S. H. Cao, H. J. Yu, J. Azad, and S. C. Ling, "Expression changes of transforming growth factor-beta1 and thrombospondin-1 in cavernous tissues of diabetic rats," Urologia Internationalis, vol. 84, no. 2, pp. 221-225, 2010.

[21] H. Jang, W. J. Bae, S. J. Kim et al., "The herbal formula KH-204 is protective against erectile dysfunction by minimizing oxidative stress and improving lipid profiles in a rat model of erectile dysfunction induced by hypercholesterolaemia," BMC Complementary and Alternative Medicine, vol. 17, no. 1, p. 129, 2017.

[22] S. J. Kim, M. R. Kim, S. Y. Hwang et al., "Preliminary report on the safety of a new herbal formula and its effect on sperm quality," The World Journal of Men's Health, vol. 31, no. 3, pp. 254-261, 2013.

[23] K. Gotanda, A. Shinbo, M. Okada et al., "Effects of combination therapy with a luteinizing hormone-releasing hormone agonist and chlormadinone acetate on rat prostate weight and plasma testosterone levels," Prostate Cancer and Prostatic Diseases, vol. 6, no. 1, pp. 66-72, 2003.

[24] W. J. Bae, U. S. Ha, J. B. Choi et al., "Protective effect of decursin extracted from Angelica gigas in male infertility via Nrf2/HO-1 signaling pathway," Oxidative Medicine and Cellular Longevity, vol. 2016, Article ID 5901098, 9 pages, 2016.

[25] A. H. Payne, J. R. Downing, and K. L. Wong, "Luteinizing hormone receptors and testosterone synthesis in two distinct populations of Leydig cells," Endocrinology, vol. 106, no. 5, pp. 1424-1429, 1980.

[26] N. Atanassova, Y. Koeva, M. Bakalska, E. Pavlova, B. Nikolov, and M. Davidoff, "Loss and recovery of androgen receptor protein expression in the adult rat testis following androgen withdrawal by ethane dimethanesulfonate," Folia Histochemica et Cytobiologica, vol. 44, no. 2, pp. 81-86, 2006.

[27] H. Chen, M. P. Hardy, and B. R. Zirkin, “Age-related decreases in Leydig cell testosterone production are not restored by exposure to LH in vitro," Endocrinology, vol. 143, no. 5, pp. 1637-1642, 2002.

[28] B. Drew and C. Leeuwenburgh, "Aging and the role of reactive nitrogen species," Annals of the New York Academy of Sciences, vol. 959, pp. 66-81, 2002.

[29] J. H. Suh, S. V. Shenvi, B. M. Dixon et al., "Decline in transcriptional activity of Nrf2 causes age-related loss of glutathione synthesis, which is reversible with lipoic acid," Proceedings of the National Academy of Sciences of the United States of America, vol. 101, no. 10, pp. 3381-3386, 2004.
[30] H. Zhang, H. Liu, K. J. Davies et al., "Nrf2-regulated phase II enzymes are induced by chronic ambient nanoparticle exposure in young mice with age-related impairments," Free Radical Biology and Medicine, vol. 52, no. 9, pp. 2038-2046, 2012.

[31] N. Sofikitis, N. Giotitsas, P. Tsounapi, D. Baltogiannis, D. Giannakis, and N. Pardalidis, "Hormonal regulation of spermatogenesis and spermiogenesis," The Journal of Steroid Biochemistry and Molecular Biology, vol. 109, no. 3-5, pp. 323-330, 2008.

[32] B. R. Zirkin and H. Chen, "Regulation of Leydig cell steroidogenic function during aging," Biology of Reproduction, vol. 63, no. 4, pp. 977-981, 2000.

[33] S. Levy and B. Robaire, "Segment-specific changes with age in the expression of junctional proteins and the permeability of the blood-epididymis barrier in rats," Biology of Reproduction, vol. 60, no. 6, pp. 1392-1401, 1999.

[34] B. R. Troen, “The biology of aging," Mount Sinai Journal of Medicine, vol. 70, no. 1, pp. 3-22, 2003.

[35] D. Harman, "Aging: overview," Annals of the New York Academy of Sciences, vol. 928, pp. 1-21, 2001.

[36] L. A. Lesniewski, D. R. Seals, A. E. Walker et al., "Dietary rapamycin supplementation reverses age-related vascular dysfunction and oxidative stress, while modulating nutrientsensing, cell cycle, and senescence pathways," Aging Cell, vol. 16, no. 1, pp. 17-26, 2017.

[37] Y. Higami and I. Shimokawa, "Apoptosis in the aging process," Cell and Tissue Research, vol. 301, no. 1, pp. 125-132, 2000.

[38] H. R. Warner, R. J. Hodes, and K. Pocinki, "What does cell death have to do with aging?," Journal of the American Geriatrics Society, vol. 45, no. 9, pp. 1140-1146, 1997.

[39] K. M. Hyman, G. Seghezzi, G. Pintucci et al., "Transforming growth factor- $\beta 1$ induces apoptosis in vascular endothelial cells by activation of mitogen-activated protein kinase," Surgery, vol. 132, no. 2, pp. 173-179, 2002.

[40] J. Massague and Y. G. Chen, "Controlling TGF- $\beta$ signaling," Genes \& Development, vol. 14, no. 6, pp. 627-644, 2000.

[41] L. W. Zhang, S. Piao, M. J. Choi et al., "Role of increased penile expression of transforming growth factor-betal and activation of the Smad signaling pathway in erectile dysfunction in streptozotocin-induced diabetic rats," The Journal of Sexual Medicine, vol. 5, no. 10, pp. 2318-2329, 2008.

[42] F. Zhou, H. Xin, T. Liu et al., "Effects of icariside II on improving erectile function in rats with streptozotocin-induced diabetes," Journal of Andrology, vol. 33, no. 5, pp. 832-844, 2012.

[43] K. Dreikorn, "Complementary and alternative medicine in urology,” BJU International, vol. 96, no. 8, pp. 1177-1184, 2005.

[44] J. Yang, Y. Wang, Y. Bao, and J. Guo, "The total flavones from Semen cuscutae reverse the reduction of testosterone level and the expression of androgen receptor gene in kidney-yang deficient mice," Journal of Ethnopharmacology, vol. 119, no. 1, pp. 166-171, 2008.

[45] Z. J. Zang, S. Y. Ji, W. Dong, Y. N. Zhang, E. H. Zhang, and Z. Bin, "A herbal medicine, saikokaryukotsuboreito, improves serum testosterone levels and affects sexual behavior in old male mice," The Aging Male, vol. 18, no. 2, pp. 106-111, 2015.

[46] H. Jang, W. J. Bae, S. J. Kim et al., “The effect of anthocyanin on the prostate in an andropause animal model: rapid prostatic cell death by apoptosis is partially prevented by anthocyanin supplementation," The World Journal of Men's Health, vol. 31, no. 3, pp. 239-246, 2013. 


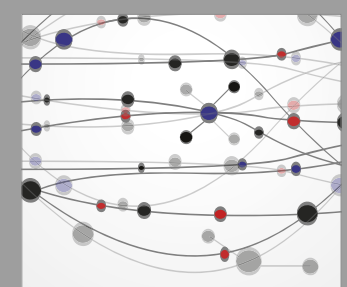

The Scientific World Journal
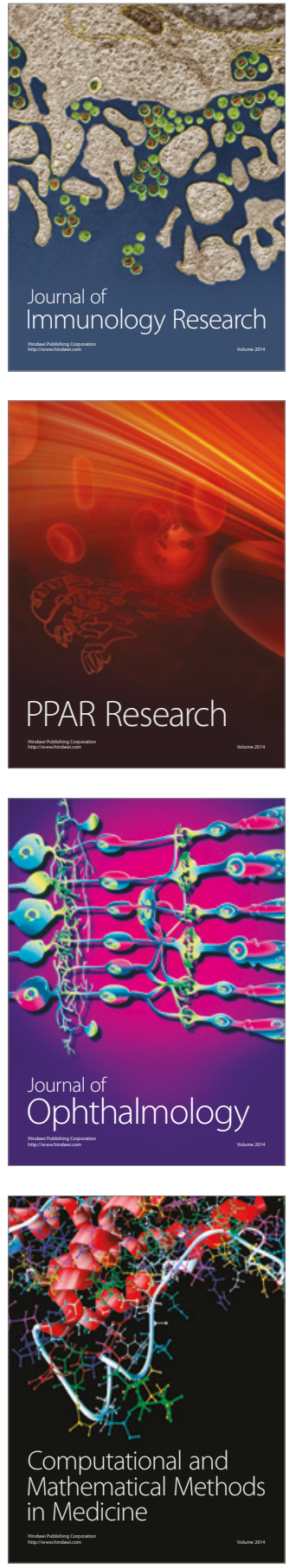

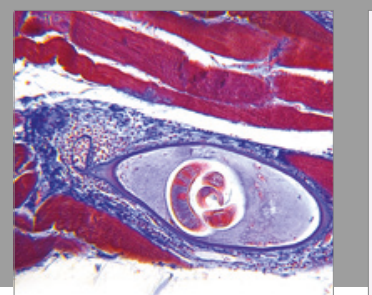

Gastroenterology Research and Practice
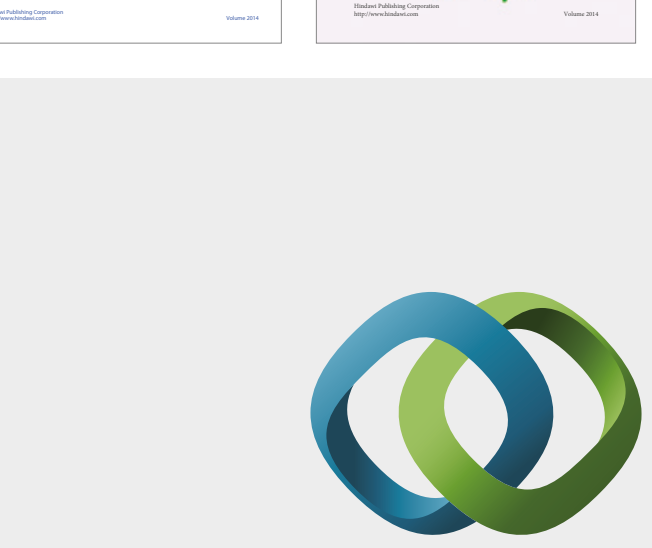

\section{Hindawi}

Submit your manuscripts at

https://www.hindawi.com
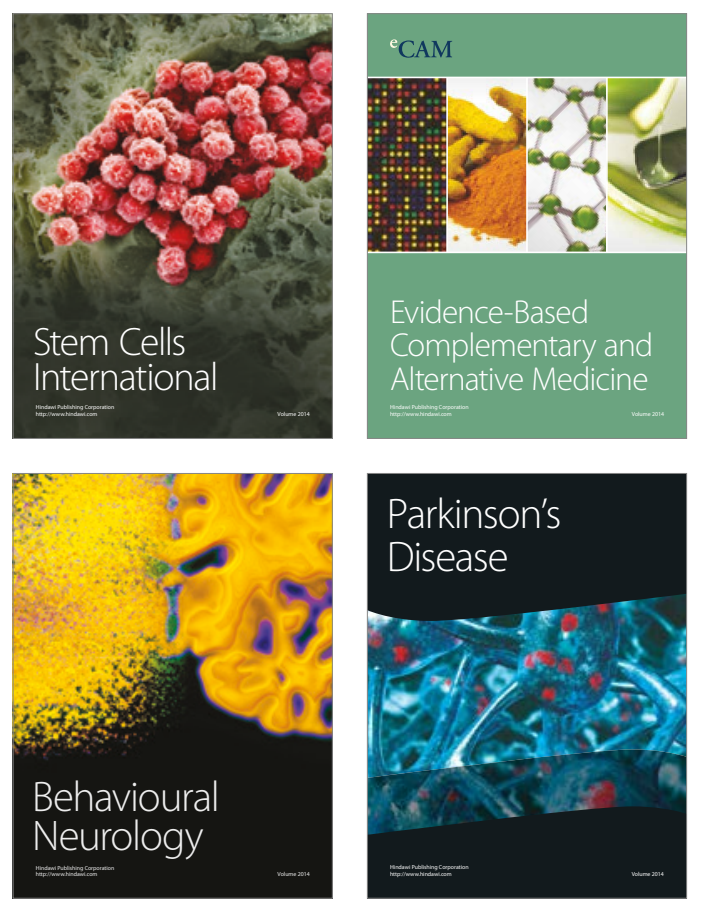
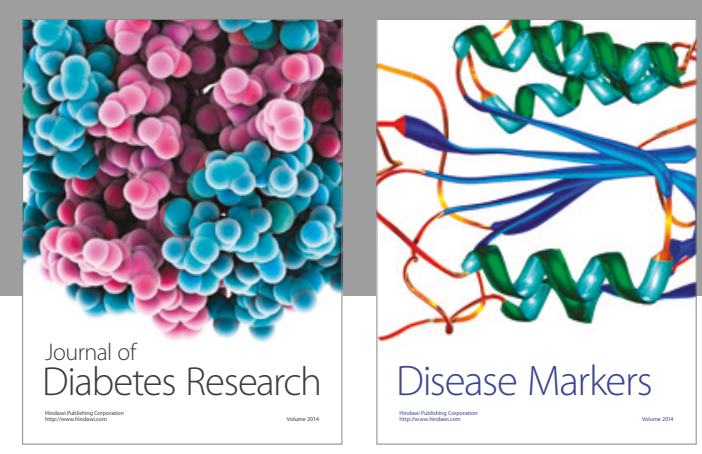

Disease Markers
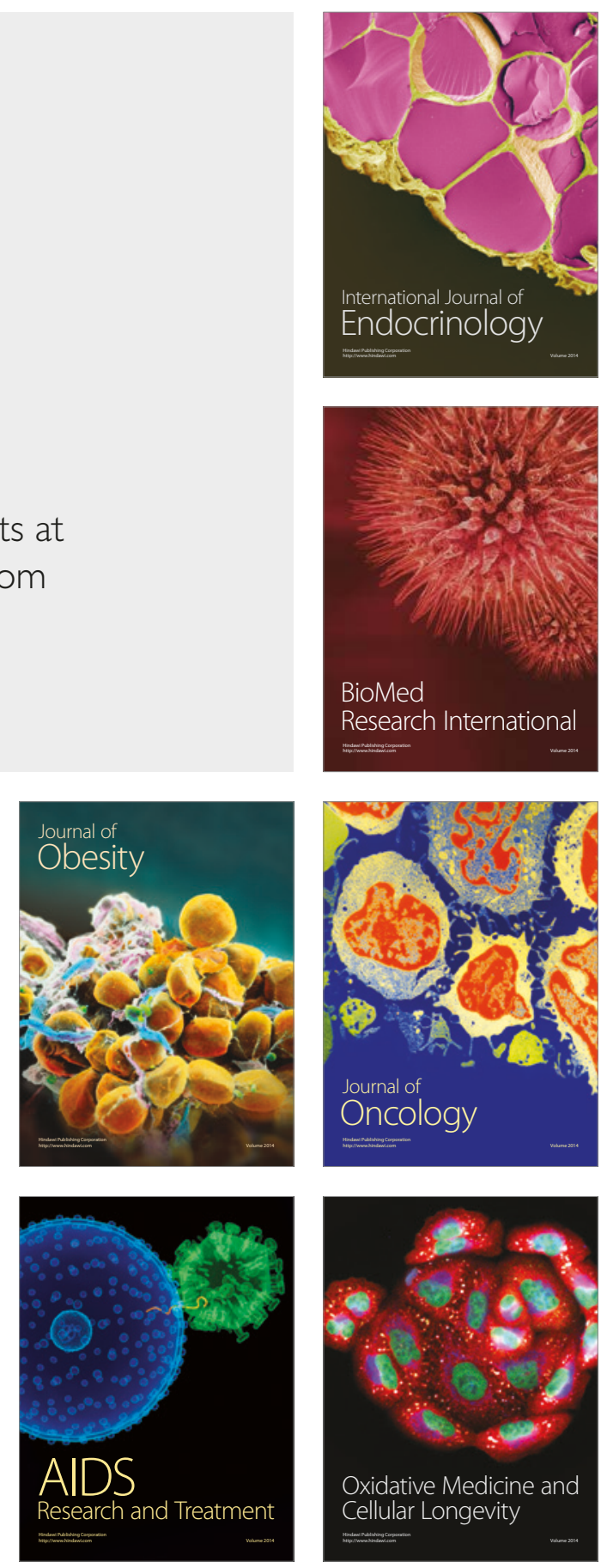